\title{
Sistem Pencatatan Laporan Tanam Dan Hasil Panen Menggunakan Sms Gateway Di Wilayah Kabupaten Bandung Barat
}

\author{
Yulianus Palopak dan Sharon Aljeazsa Lovelyjeal Silalahi \\ Fakultas Teknologi Informasi, Universitas Advent Indonesia
}

\begin{abstract}
Abstrak
Tujuan membangun Sistem Pencatatan Laproan Tanam dan Hasil Panen Menggunakan SMS Gateway adalah sebagai alat pendukung untuk mengirimkan informasi kepada petani dengan efisien dan cepat. Teknologi Informasi yang digunakan dalam membangun Aplikasi SMS Gateway untuk Sistem Pencatatan Laporan Tanam dan Hasil Panen di Dinas Pertanian berbasis PHP dan menggunakan Gammu sebagai antarmuka yang menghubungkan handphone atau modem dengan komputer. Sebagai Metode Penelitian digunakan Metode SDLC. Sistem ini menggunakan modem dan Handphone sebagai media pengiriman dan penerima pesan masuk. Sistem ini dibangun dengan cara mengkonfigurasikan gammu agar dapat bekerja dengan baik, membuat sistem yang mampu membalas sms registrasi dan informasi dengan auto replay. Dari hasil penelitian dan pengujian yang telah dilaksanakan, diperoleh kesimpulan bahwa Gammu dapat dikonfigurasikan dengan modem dan database melalui device manager. Sistem ini bisa mendeteksi pesan masuk pada inbox yang dikirim oleh petani dan bisa mengirimkan balasan sesuai dengan kebutuhan petani.
\end{abstract}

Kata - kata kunci: PHP, SMS Gateway, Gammu, AutoReply.

\section{Planting and Harvesting Report Documentation System Using SMS Gateway at Kabupaten Bandung Barat}

\begin{abstract}
The purpose of establishing System of planting and harvesting reports based on SMS Gateway is as a supporting tool to send information to farmers efficiently and quickly. Information Technology that being used to build SMS Gateway Application for System of Planting and Harvesting Report in Agriculture Department based on PHP and using Gammu as interface that connects mobile phone or modem with computer. As Method Research used SDLC method. This system uses a modem and Mobile as a medium of sending and receiving incoming messages. This system is built by configuring your gammu to work properly, creating a system capable of replying to sms registrations and information with autoreplay. From the results of research and testing that have been implemented, obtained the conclusion that Gammu can be configured with modem and database through device manager. This system can detect incoming messages in the inbox sent by the farmer and can send a reply according to the needs of farmers.
\end{abstract}

\section{Pendahuluan}

Kemajuan teknologi yang semakin cepat mempengaruhi berbagai aspek kehidupan. Kebutuhan akan akses informasi dan perkembangan teknologi membawa perubahan pada berbagai macam sistem di berbagai bidang. Indonesia merupakan salah satu negara yang dikenal sebagai agraris karena sebagian besar penduduknya bekerja sebagai petani dan memiliki lahan agraris. Para petani di Indonesia membutuhkan informasi yang cepat dan terperinci serta up to date tentang informasi lahan pertanian, tanaman, harga produk hasil panen petani. Oleh karena itu diperlukan media penyaluran informasi yang bisa melaporkan laporan panen dan sistem menggunakan SMS Gateway. Teknologi SMS (Short Message Service) saat ini mengalami perkembangan baik dari segi fungsi maupun penggunaan. SMS Gateway merupakan sistem yang bisa mengirim dan juga menerima pesan secara otomatis. Oleh karena itu dengan adanya sistem SMS Gateway yang berfungsi sebagai media informasi untuk melakukan pelaporan hasil tanam dan hasil panen dan menanyakan informasi kebutuhan pasar, prediksi harga untuk bulan kedepannya. Sistem ini juga dapat membantu dinas pertanian untuk mengumpulkan data yang diperlukan oleh petani-petani. 


\section{Landasan Teori}

Sistem Informasi

Sistem merupakan kumpulan dari sub sistem atau komponen apapun baik fisik ataupun non fisik yang saling berhubungan satu sama lain dan bekerja sama secara harmonis untuk mencapai satu tujuan tertentu (Susanto, 2013:22).

\section{SMS (Short Message Service)}

Short Message Service adalah layanan untuk mengirim dan menerima pesan tertulis (teks) dari maupun kepada perangkat bergerak (mobile devices) (Maulana, 2015).

\section{XAMPP}

Xampp adalah aplikasi web server instan yang dibutuhkan untuk membangun aplikasi berbasis web (sumber: http://www.apachefriends.org).

\section{SMS Gateway}

SMS Gateway adalah aplikasi SMS yang bersifat dua arah (two-way SMS) yang dapat membantu dalam menjalin interaksi dengan pelanggan melalui SMS atau bisa juga diartikan sebagai sebuah gerbang yang menghubungkan antara komputer dengan client melalui SMS.SMS Gateway diguunakan untuk mengirim dan atau menerima SMS, digunakan pada aplikasi bisnis baik untuk kepentingan broadcast promosi, service informasi terhadap pengguna, penyebaran content atau produk/jasa (sumber: http://SMSCenterGateay.com)

\section{Basis Data}

Basis Data adalah kumpulan data dari berbagai sumber yang mempunyai arti implisit sehingga data yang terkumpul secara acak dan jika tidak memiliki arti maka tidak dapat disebut sebagai basis data (Ramez, 2000).

\section{MySQL}

MySQL merupakn salah satu jenis server untuk basisdata yang sangat terkenal dan banyak digunakan untuk membangun aplikasi web yang menggunakan basisdata sebagai sumber dan pengolahan datanya. MySQL dikembangkan oleh sebuah perusahaan dari swedia bernama MySQL AB yang pada saat itu bernama Tcx DataKonsult AB tahun 1994-1995 (Arief, 2011:152)

\section{UML( Unified Modelling Language)}

Unified Modeling Language (UML) merupakan bahasa standard yang digunakan untuk visualisasi, membangun dan menetapkan serta untuk mendokumentasikan artefak suatu sistem perangkat lunak (Hend, 2006).

\section{Analisis Perancangan Sistem Analisis Kebutuhan Fungsi Sistem}

1. Fungsi untuk melakukan registrasi petani.

2. Fungsi untuk mengirim pesan laporan hasil tanam kepada Dinas Pertanian.

3. Fungsi untuk mengirim pesan laporan hasil panen kepada Dinas Pertanian.

4. Fungsi untuk menerima pesan dari Dinas Pertanian.

\section{Analisa Sistem \\ Use Case Diagram}

Use Case merupakan kumpulan skenario yang menggambarkan interaksi antara user dan system. Use case diagram menampilkan hubungan antara himpunan use case dan aktor. Berikut ini adalah gambar use case diagram dan keterangan pelaku-pelaku. Berikut gambar use case diagram dan keterangan pelaku dari use case yang didapat dari analisa sistem kebutuhan sistem.

Berikut diagram use case dari sistem pencatatan laporan panen dan hasil tanam menggunakan sms gateway: 


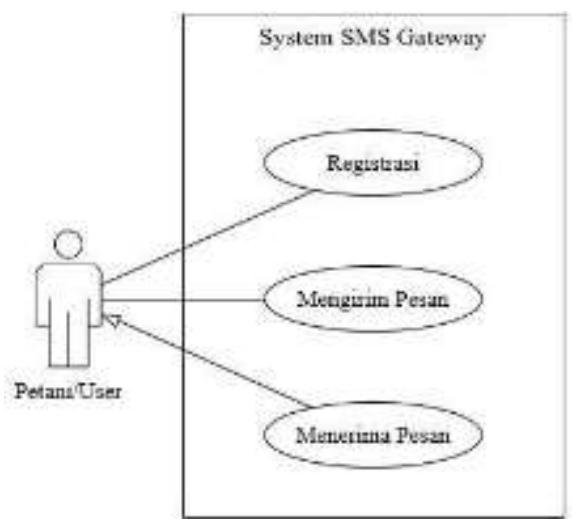

Gambar 1 Use Case Diagram

Pada Gambar 1 Use Case Diagram menjelaskan pelaku-pelaku yang terdapat dalam sistem ini adalah:

1. Sistem:

- Memproses verifikasi yang dilakukan dinas pertanian.

- Memproses dan menyimpan informasi yang dikumpulkan oleh dinas pertanian.

2. User (Petani):

- Melakukan registrasi.

- Mengirim pesan berupa laporan hasil panen dan hasil tanam.Menerima pesan dari sistem berupa informasi kebutuhan pasar.

3. Use Case dari sistem ini adalah :

- User/Petani melakukan registrasi melalui sistem yang disediakan oleh Dinas Pertanian.

- Setelah selesai melakukan registrasi, sistem akan mengirimkan kode verifikasi kepada petani.

- User/Petani dapat mengirim pesan berupa laporan hasil tanam dan hasil panen dan dapat menerima pesan berupa informasi kebutuhan pasar dari sistem.

\section{Class Diagram}

Class Diagram dari rancangan sistem informasi ini dapat dijelaskan melalui gambar berikut ini:

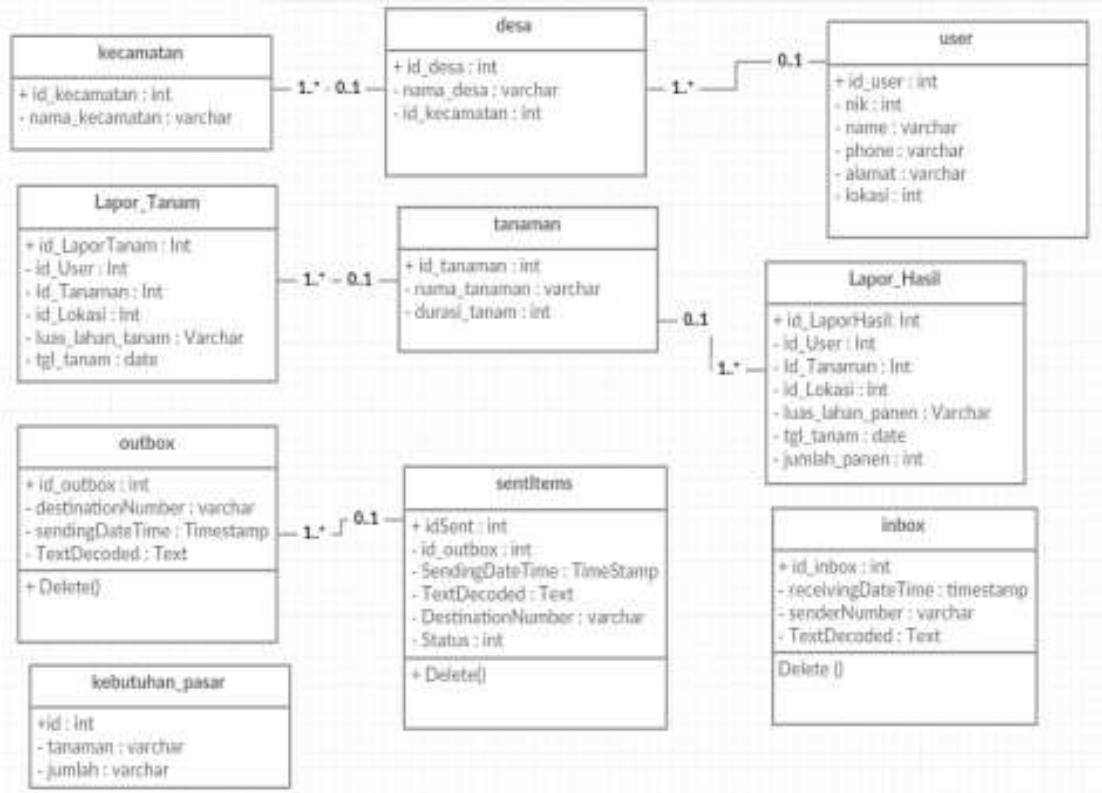

Gambar 2 Class Diagram 


\section{Hasil dan Perancangan Tampilan Home}

Pada Gambar 3 adalah tampilan home pada sistem saat user mengakses sistem tersebut. User inilah yang dapat melakukan beberapa fungsi untuk sistem sms gateway ini.

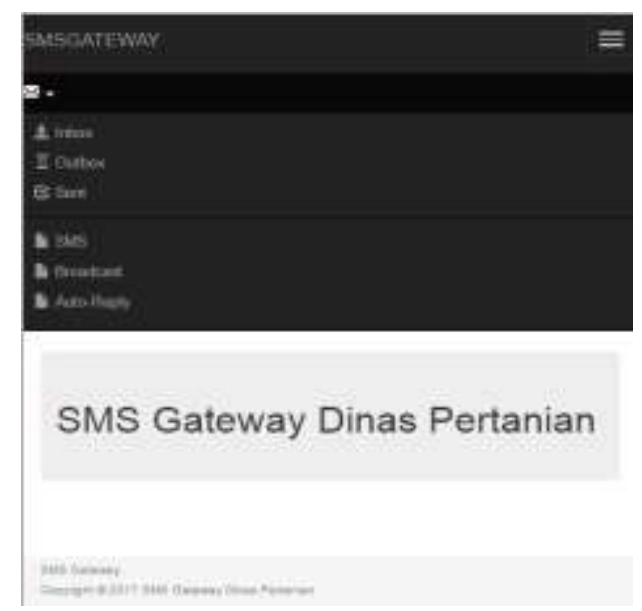

Gambar 3 Tampilan Home

\section{Tampilan Inbox}

Pada Gambar 4 menampilkan menu inbox. Setiap pesan yang masuk akan ditampilkan di dalam menu inbox. Tampilan menu inbox terdapat fungsi Delete untuk menghapus pesan.

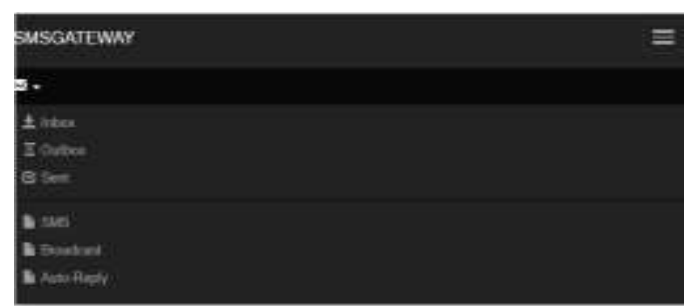

\pm Inbox

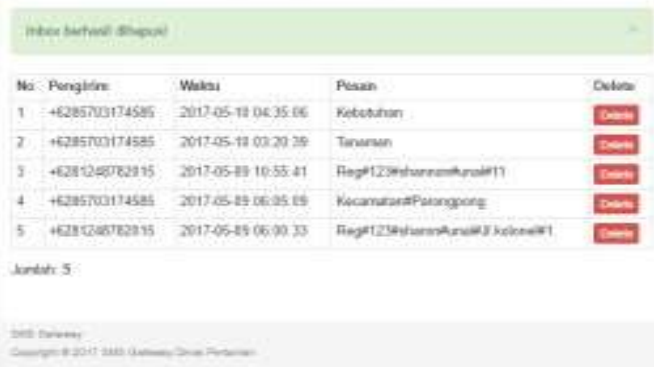

Gambar 4 Tampilan Inbox

\section{Tampilan Outbox}

Pada Gambar 5 menampilkan menu outbox, setiap pesan yang akan dikirim tapi pending atau gagal dikirim akan ditampilakan di menu outbox dan terdapat fungsi delete untuk menghapus pesan. 


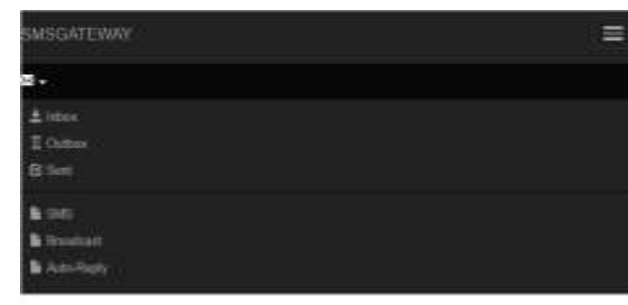

Z Outbox
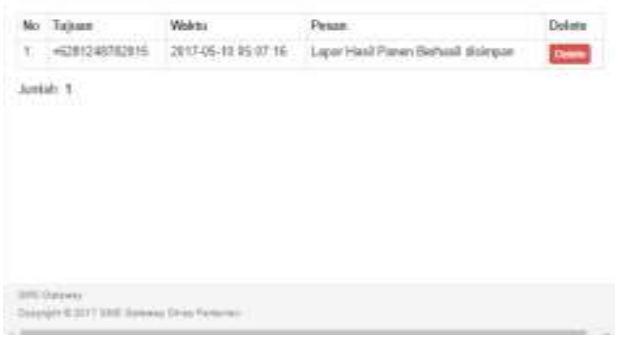

Gambar 5 Tampilan Outbox

\section{Tampilan Sent Items}

Pada Gambar 6 menampilkan menu sent. Menu sent adalah setiap pesan yang terkirim akan tersimpan didalam menu sent. Menu sent terdapat fungsi delete untuk menghapus pesan-pesan yang lama.
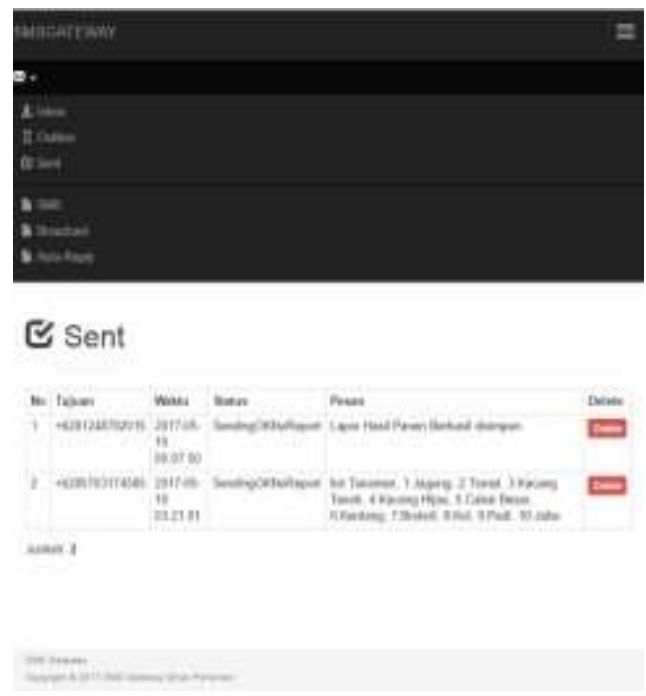

Gambar 6 Tampilan Sent Items

\section{Tampilan Create Message}

Pada Gambar 7 menampilkan menu sms. Menu ini berfungsi untuk membuat pesan baru dan mengirimkan pesan tersebut. 


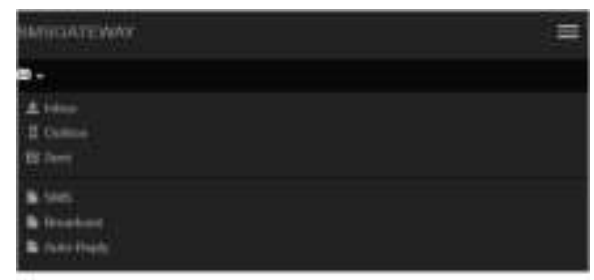

SMS

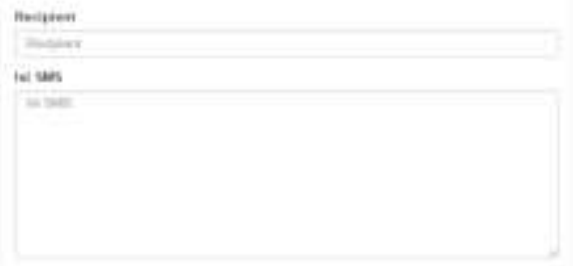

Gambar 7 Tampilan Create Message

\section{Tampilan Menu Brodcast}

Pada gambar 8 merupakan tampilan menu broadcast yang berfungsi untuk mengirimkan pesan ke semua petani yang terdaftar di table user.

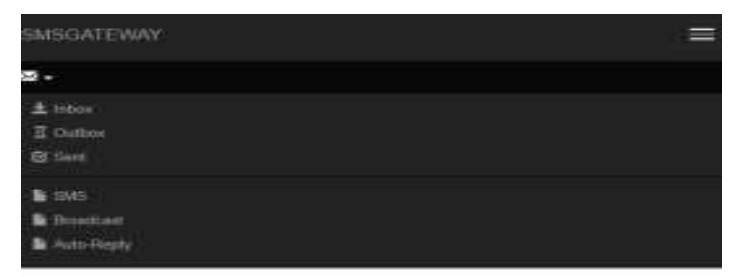

SMS

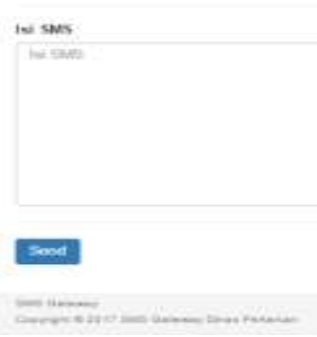

Gambar 8 Tampilan Menu Broadcast

\section{Rencana Pengujian}

Adapun Rencana Pengujian sistem yang akan diuji dengan teknik pengujian Black Box penulis akan kelompokkan dalam table dibawah ini:

Tabel 1 Rencana Pengujian

\begin{tabular}{|l|l|l|l|}
\hline No & Komponen Sistem yang di Uji & Butir Uji & Jenis Pengujian \\
\hline 1 & Menu SMS & Tombol Delete & Black Box \\
\hline 2 & Menu Create SMS & Tombol Sent & Black Box \\
\hline 3 & Menu AutoReply & AutoReply & Black Box \\
\hline
\end{tabular}




\section{Hasil Pengujian}

Berikut ini adalah kasus untuk menguji perangkat lunak yang sudah dibangun dengan menggunakan metode Black Box berdasarkan Tabel 1.

Tabel 2 Hasil Pengujian

\begin{tabular}{|l|l|l|l|l|}
\hline No & Form Diuji & Skenario Diuji & Hasil yang diharapkan & Hasil Pengujian \\
\hline 1 & $\begin{array}{l}\text { Menu SMS (Inbox } \\
\text { dan Outbox) }\end{array}$ & $\begin{array}{l}\text { Menghapus } \\
\text { Pesan di menu } \\
\text { inbox dan } \\
\text { outbox }\end{array}$ & $\begin{array}{l}\text { Ketika sms yang berada } \\
\text { di menu inbox dan } \\
\text { outbox di hapus maka } \\
\text { akan terhapus juga di } \\
\text { dalam database. }\end{array}$ & Diterima [ $\checkmark$ ] \\
\hline 2 & Menu Create SMS & $\begin{array}{l}\text { Mengirim pesan } \\
\text { dengan format } \\
\text { telepon yang } \\
\text { benar }\end{array}$ & $\begin{array}{l}\text { Ketika pesan dan nomor } \\
\text { yang di input benar } \\
\text { maka pesan akan } \\
\text { masuk di menu sent } \\
\text { dan di database. }\end{array}$ & Diterima [ $\checkmark$ ] \\
\cline { 3 - 5 } & $\begin{array}{l}\text { Mengirim pesan } \\
\text { dengan format } \\
\text { yang salah }\end{array}$ & $\begin{array}{l}\text { Ketika pesan akan } \\
\text { dikirim dengan } \\
\text { menggunakan format } \\
\text { yang salah, pesan tidak } \\
\text { akan melakukan } \\
\text { pengiriman. }\end{array}$ & Diterima [ $\checkmark$ ] \\
\hline 3 & Menu AutoReply & $\begin{array}{l}\text { Mengirim pesan } \\
\text { dengan format } \\
\text { pesan yang } \\
\text { sudah } \\
\text { ditentukan }\end{array}$ & $\begin{array}{l}\text { Ketika Format yang } \\
\text { diinput sesuai maka } \\
\text { akan mendapat pesan } \\
\text { balasan.. }\end{array}$ & Diterima [ $\checkmark$ ] \\
\cline { 3 - 5 } & $\begin{array}{l}\text { Ketika format yang } \\
\text { dikirimkan tidak sesuai } \\
\text { maka tidak akan } \\
\text { mendapatkan sms } \\
\text { balasan. }\end{array}$ & Ditolak [ ] \\
\hline
\end{tabular}

\section{Kesimpulan Hasil Pengujian}

Berdasarkan hasil pengujian perangkat lunak maka penulis menarik kesimpulan bahwa perangkat lunak sudah berjalan secara fungsional dan mengelurkan informasi sesuai dengan yang diharapkan.

\section{Kesimpulan dan Saran \\ Kesimpulan}

Setelah melakukan penelitan dan perancangan sistem SMS Gateway maka penulis mengambil kesimpulan bahwa:

1. Sistem SMS Gateway akan mempermudah petani dalam melakukan pelaporan kepada dinas pertanian.

2. Sistem ini juga dapat dibangun dengan cara merancang fungsi-fungsi sesuai dengan kebutuhan pengembangan sistem sms gateway.

3. Aplikasi SMS Gateway dapat dibangun menggunakan Gammu.

\section{Saran}

Berdasarkan perancangan sistem SMS Gateway yang telah dibuat, penulis sarankan adalah sebagai berikut:

1. Aplikasi ini bukan hanya untuk melaporkan hasil tanam dan panen tapi juga dapat dikembangkan untuk melihat informasi harga tanaman dipasar yang bisa dibagikan ke masyarkat serta dapat melihat statistik dari perkembangan tanaman yang di panen maupun di tanam oleh petani. 


\section{Referensi}

1. Arief, M. R.2011. Pemograman Web Dinamis menggunakan PHP dan MySQL. Yogyakarta: Andi.

2. Maulana, Sofyan. 2015. 5 Proyek Populer SMS Gateway, Jakarta: PT. Elex Media Komputindo.

3. Mulyanto, Agus. 2009. Sistem Informasi Konsep dan Aplikasi. Yogyakarta: Pustaka Pelajar.

4. Nugroho, Adi. 2012. Perancangan dan Implementasi Sistem Basis Data, Bandung: Andi Publisher.

5. Susanto, Azhar. 2013. Sistem Informasi Akuntansi. Bandung: Lingga Jaya.

6. Sutabri, Tata. 2011. Konsep Sistem Informasi. Yogyakarta: Andi. 